\title{
IMPLEMENTATION OF INCLUSIVE MEASURES TO SUPPORT PUPILS OF DIFFERENT SOCIO-ECONOMIC AND CULTURAL ENVIRONMENT
}

\section{Katarína Dubělčíková}

One of the projects aimed at the introduction of inclusive measures is the project Support of Inclusion in the Moravian-Silesian Region. The project involves eight primary schools, one secondary school, two pedagogical psychological counselling offices, a DTIC (District Facility for Further Training of Teaching Staff and Information Centre), and the non-government non-profit organization Společně-Jekhetane, CIC [o.p.s.].

The aim of introducing positive inclusive conditions is to support pupils from marginalized groups, pupils of different socio-economic and cultural environment and pupils with special educational needs. It focuses on such conditions that will help the target group pupils experience school success, facilitate their transition from one level of education to another and allow them to integrate themselves into the society.

In the framework of the implementation of the project, emphasis is mainly placed on networking. The aim is to establish cooperation among individual entities, namely, the schools, the educational and psychological counselling offices and the NGOs. This mutual cooperation should be directed toward providing support to target group pupils and to the families of these pupils. To do so, a cooperation and collaboration of stakeholders in inclusion is necessary. It is important that the cooperating entities have established real communication and cooperation which will lead to mutual understanding and effective transmission of information. School counselling offices, which include the special needs teachers and the school psychologists, play a key role here. Each of the participating schools thus has specialized staff at their disposal directly on site. An integral part is formed by the school assistants who work in tandems with the teachers. Their work duties are, in particular, the communication with teachers, pupils and families. The answer to the question of how to achieve the support of the target group pupils may be found in the development of co-operation and competences of all the agents involved in education, whether directly or indirectly. Of course, the interest and motivation of parents to be involved must not be omitted. The support of the whole community from officials with decision-making powers to end users (pupils, parents) is needed for inclusion to be implemented.

The project activities aim to support target group pupils and, at the same time, they focus on the support and development of competences of teachers. These activities include: 


\section{Primary and Secondary Schools:}

- Increasing the competences of teaching and non-pedagogical staff to work with the pupils and families of the target group

- Development of key competences and literacy in the framework of after-school clubs

- Establishment of the position of a special pedagogue and a psychologist

- Support by means of a school assistant

- Methodological support of the special needs teacher, psychologist and school assistant in the form of training and supervision

- Intervisional expert guidance of the school in creating conditions for inclusive education

- Activities aimed at facilitating the transition of children and pupils from one level of education to another, including tutoring at school, after-school groups for the development of key competences in the framework of informal clubs. Tutoring can also be carried out in cooperation with an NGO where the NGO worker visits the families.

- The development of cooperation among the teaching staff, social and health-care services and the family in education primarily through parents' clubs where the parents meet the teachers and other professionals once a month. The clubs focus on developing and strengthening partnership of the professionals with the parents, the transmission of information regarding the education of pupils, how to work with them at home and what to focus on. The clubs are attended by the parents, the inclusion coordinator, other professionals of the school counselling office and social, health-care or other spheres. They address the current needs of parents and pupils.

The establishment of the position of special needs teacher and school psychologist will increase the possibility of early intervention towards the support of target group pupils and their integration into their classes. By ensuring the presence of a school assistant at the school, the establishment of more efficient cooperation with the pupil's family will become possible, especially enabling the assistant to influence the family environment.

\section{Pedagogical-Psychological Counselling Offices:}

One of the major activities of the pedagogical-psychological counselling office is the support of school counselling offices by organizing educational activities both for schools and the teaching staff, and for the parents, methodological support and supervision of the project activities. The pedagogical-psychological counselling offices are expected to cooperate closely with the schools and NGOs.

\section{Non-Governmental Non-Profit Organisations:}

- The close cooperation with schools and families - the identification of their current needs and efficient response to the identified needs 
- Cooperation with the pedagogical-psychological counselling office - according to the current needs and requirements of parents and schools.

- Activities aimed at establishing contact of the school with the family of the pupil, learning the environment, location, determining the needs and possibilities of the support to the pupil's family

- Activities for the teaching team focused on understanding the different concept of education in Roma families

- Methodical guidance of school assistants

- Activities for Roma and non-Roma parents aimed at removing the barriers of mutual prejudices in the form of social events at neutral venues Parents have the opportunity to get to know each other in the context of informal meetings.

- Activities for Roma parents which will be focused on the development of parental competence and understanding of the importance of education for their children in the form of workshops.

- In difficulties dealing with the school, the parents are provided with individual support communicating with the pedagogical worker which can help prevent conflicts caused by incorrect interpretation of the said. Thanks to the project, it happens more and more often that the staff of NGOs are invited by the school to cooperate with families of pupils at risk of exclusion. It especially concerns such activities that help establish a closer cooperation with the family, aiming at improving the pupil's grades, attendance and behaviour.

- Part of the auxiliary activities may be tutoring.

The project helps open multiple possibilities to support pupils of marginalised groups, and open and expand horizons. Through the activities, the families become closer to the school which provides the opportunity to remove the barrier between teachers, parents and pupils.

In the course of one year, cooperation was successfully established between schools and non-profit organizations which the schools perceive as positive experience, particularly in regard to the cooperation with families. It is easier to work on producing plans to support the pupils and motivate the parents to cooperation. Among other things, this leads to the creation of partnership between parents and teachers. The experience of social workers of NGOs are passed on to the school assistants. In the framework of methodological meetings, experience and examples of good practice are shared. At the same time, there is room for the development of social competences.

Once per the duration of the project, each school organizes a discussion for the teaching staff. The aim of this discussion is to bring the Roma culture closer and point out the differences in the education of Roma families which helps overcome the barriers between the schools staff and the families from different social and cultural environment.

In conclusion, I want to once again underline the need to interconnect all of the agents involved in the inclusion measures. This involves looking for possibilities to help the pupils who are at risk of exclusion. The possibility to use the services of the school 
psychologist, the special needs teacher and the school assistant on the site at school makes the support of target group pupils more efficient. There is a greater chance to prevent exclusion from the course of education. Thanks to tutoring either directly at schools or in families, the pupils have the opportunity to experience academic success which increases their motivation to continue their education. At the same time, the teaching staff have the opportunity to develop their social skills within the project to learn that education is not just a question of studying but that every pupil does have his or her social background. Their education and learning is thus in a significant way influenced by the social environment in which they grow up.

\section{Author}

Mgr. Katarína Dubělčíková

Společně - Jekhetane, o.p.s.

U Tiskárny 3, Ostrava, The Czech Republic

inkluze@jekhetane.cz 